\title{
Anatomical study of nutrient foramina in humerus
}

\author{
Shuhbhangi B. Ghule ${ }^{1, *}$, Bhushan Vitore' ${ }^{2}$, Amrut A. Mahajan ${ }^{3}$ \\ ${ }^{\mathbf{1}}$ Associate Professor, ${ }^{\mathbf{2}}$ Assistant Professor, ${ }^{3}$ Professor and Head, Dept. of Anatomy, Dr. Ulhas Patil Medical College \& Hospital, \\ Maharashtra, India
}

*Corresponding Author:

Email: shukwagh@gmail.com

Received: $22^{\text {nd }}$ March, 2018

Accepted: $30^{\text {th }}$ March, 2018

\begin{abstract}
Introduction: Knowledge of nutrient foramina is important in surgical procedures. Objective of present study is to know the number, location and direction of nutrient foramina in diaphysis of humerus and to test the significant difference of total length and foraminal index on right and left side separately.

Materials and Methods: Total 100 dried humerii of unknown sex (52 of right and 48 of left side) were taken for present study. The identification of nutrient foramen was confirmed with the help of magnifying lens and metallic wire. The total length of humerus and distance of nutrient foramen from proximal end of humerus was measured by sliding caliper and osteometric board. Foraminal index was also calculated.

Results: All the examined bones showed single diaphyseal nutrient foramen. Majority of foramina (81\%) were present on middle $1 / 3$ of anteromedial surface of shaft of humerus. The direction of these foramina was similarly found in all bones i.e. towards the elbow joint. There were no significant differences between right and left side for total length and foraminal index.

Conclusion: An accurate knowledge of the location of nutrient foramina is important in surgical procedures like reduction of fracture, bone grafting and microsurgical vascularized bone transplantation.
\end{abstract}

Keywords: Humerus, Nutrient foramina, Number, Location, Direction, Foraminal index.

\section{Introduction}

An opening into the shaft of bone for passage of blood vessels for its nourishment and growth is called as nutrient foramen. ${ }^{1}$ The long bone is supplied by a nutrient artery, which enters the bone obliquely through the nutrient foramen, which is directed away, as a rule, from the growing end. ${ }^{2}$ It is well known that they seek the elbow and flee from the knee. ${ }^{3}$ The humerus is the largest and longest bone in the upper limb. It is supplied by nutrient artery which is usually a branch of brachial artery. It enters into the bone from anteromedial surface at middle $1 / 3$ of the shaft of humerus. ${ }^{4}$ Common sites of fractures are at the surgical neck, middle of the shaft and at the supracondylar region. Junction of the upper and middle thirds of the shaft possesses poor blood supply; hence a fracture at this region may be associated with delayed union or non-union. ${ }^{5}$ Damage to nutrient vessels, excessive stripping or injury to periosteum and muscles are few causes for loss of blood supply to the fractured site. ${ }^{6}$ Nutrient artery is usually ruptured during fracture of shaft of humerus so it is important to have anatomical knowledge of nutrient foramen during surgical procedures. The aim of the present study is to know the number, location and direction of nutrient foramina in diaphysis of humerus and to test the significant difference of total length and foraminal index on right and left side separately.

\section{Materials and Methods}

The present study was conducted on 100 dried humerii with unknown sex. Among 100 bones studied, 52 were right and 48 were left sided. The dried humerii were collected from MGM Medical College and Government Medical College, Aurangabad and from Department of Anatomy, Dr. Ulhas Patil Medical College, Jalgaon. All humerii were examined for number, location and direction of nutrient foramina on its diaphysis. A magnifying lens was used to observe the foramina. Metallic wire was passed through each nutrient foramen (NF) (Fig. 1) to confirm their patency. If extra foramen present, they were compared with the larger foramen and the larger foramen was considered dominant foramen (DF) and others as secondary foramen (SF). Instruments used for the study (Fig. 2) were magnifying lens, metallic wire, sliding caliper, osteometric board. The total length of humerii (TL) and distance of nutrient foramen from the proximal end (DNF) was also measured with the help of sliding caliper and osteometric board. Right and left sided bones were studied separately to calculate total length and foraminal index to test the significant difference. Foraminal index can help clinicians to locate the nutrient artery.

Foraminal index was calculated by using the Hughes $\mathrm{H}^{7}$ formula, $\mathrm{FI}=(\mathrm{DNF} / \mathrm{TL}) \times 100$ 


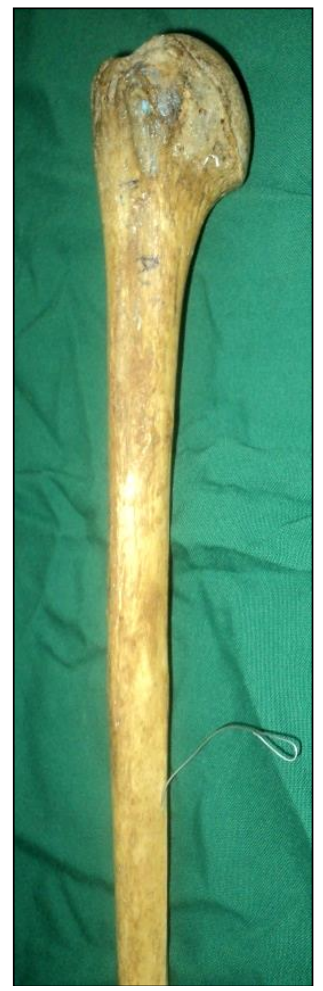

Fig. 1: Photograph showing location of nutrient foramen in humerus

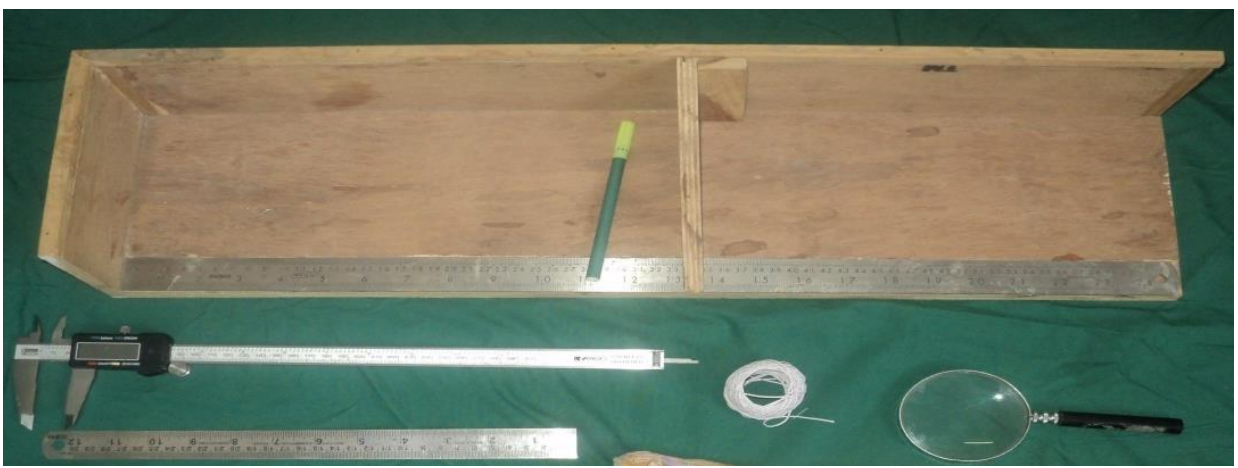

Fig. 2: Photograph showing instruments used for measurements of humerii

\section{Results}

Parameters were studied and analyzed statistically using a standard computer program.

All the examined bones showed single diaphyseal nutrient foramen (Table 1).

Table 1: Number of nutrient foramen on humerus

\begin{tabular}{|c|c|c|c|c|c|}
\hline \multirow{2}{*}{$\begin{array}{c}\text { No. of nutrient foramen on } \\
\text { humerus }\end{array}$} & \multicolumn{2}{|c|}{ Right } & \multicolumn{2}{c|}{ Left } & Both \\
\cline { 2 - 6 } & Number & Percentage & Number & Percentage & Percentage \\
\hline 1 & 52 & 100 & 48 & 100 & 100 \\
\hline
\end{tabular}

Majority of the bones i.e. $81 \%$ have nutrient foramen located on anteromedial surface (middle 1/3) of shaft of humerus. Next common position was medial

Table 2: Location of nutrient foramen on humerus border (middle 1/3) of shaft of humerus i.e.7\%, followed by posterior surface (middle $1 / 3$ ), medial border (lower 1/3), anteromedial surface (lower 1/3) (Table 2)

\begin{tabular}{|c|c|c|c|c|c|c|}
\hline Location of nutrient foramen on & \multicolumn{2}{|c|}{ Right } & \multicolumn{2}{c|}{ Left } & \multicolumn{2}{c|}{ Both } \\
\cline { 2 - 7 } humerus & Number & Percentage & Number & Percentage & Number & Percentage \\
\hline Antero Medial Surface (Lower 1/3) & 1 & 1.92 & 1 & 2.08 & 2 & 2 \\
\hline Antero Medial Surface (Middle 1/3) & 41 & 78.85 & 40 & 83.33 & 81 & 81 \\
\hline
\end{tabular}




\begin{tabular}{|l|l|l|l|l|l|l|}
\hline Antero Medial Surface (Upper 1/3) & 0 & 0.00 & 1 & 2.08 & 1 & 1 \\
\hline Posterior Surface (Middle 1/3) & 3 & 5.77 & 1 & 2.08 & 4 & 4 \\
\hline Medial Border (Middle 1/3) & 5 & 9.62 & 2 & 4.17 & 7 & 7 \\
\hline Medial Border (Lower 1/3) & 2 & 3.85 & 3 & 6.25 & 5 & 5 \\
\hline
\end{tabular}

The mean length of the bone for right side was 30.18 and for the left side was 29.92. The unpaired $t$ test was conducted to test the significant difference.
The $p$ value of the test was $0.5(>0.05)$ showed no significant difference between right and left side for total length of the humerus (Table 3 ).

Table 3: Total Length of humerus (cm)

\begin{tabular}{|l|c|c|c|c|}
\hline \multicolumn{1}{|c|}{ Total Length of humerus } & Mean & S.D. & t value & p value \\
\hline Right & 30.18 & 1.95 & \multirow{2}{*}{0.68} & 0.5 \\
\hline Left & 29.92 & 1.98 & & \\
\hline
\end{tabular}

The mean foraminal index was 56.31 for right side and 56.88 for left side. The unpaired $\mathrm{t}$ test was conducted to test the significant difference. The $\mathrm{p}$ value was $0.67(>0.05)$ showed no significant difference between right and left sided foraminal index (Table 4)

Table 4: Showing mean calculation of foraminal index (FI) separately on right and left side

\begin{tabular}{|l|c|c|c|c|c|c|}
\hline Humerii & $\begin{array}{c}\text { Mean of total } \\
\text { length }(\mathbf{c m})\end{array}$ & $\begin{array}{c}\text { Mean distance of nutrient } \\
\text { foramen from proximal end of } \\
\text { bone (cm) }\end{array}$ & FI & S.D. & $\begin{array}{c}\mathbf{t} \\
\text { value }\end{array}$ & $\begin{array}{c}\mathbf{p} \\
\text { value }\end{array}$ \\
\hline Right & 30.18 & 16.99 & 56.31 & 6.07 & \multirow{2}{*}{0.42} & \multirow{2}{*}{0.67} \\
\hline Left & 29.92 & 16.98 & 56.88 & 7.31 & & \\
\hline
\end{tabular}

Direction of nutrient foramen in all the bones were directed towards elbow joint i.e. away from growing end

\section{Discussion}

Location and number of nutrient foramina in bones is very important for surgical procedures. We compared our findings with the findings of previous workers. In the present study of 100 dried humerii, we found all studied humerii had single nutrient foramen directed towards the elbow joint. Among them $81 \%$ foramina were located on middle $1 / 3$ of anteromedial surface of shaft of humerus.

According to Laing (1956) ${ }^{8} 93 \%$ of humerii had single nutrient foramen. Yaseen et al. $(2014)^{9}$ in their study observed that $79 \%$ of humerii had single nutrient foramen, among them, $88.5 \%$ of foramina were present on anteromedial surface. According to Khan et al. (2014), ${ }^{10} 90 \%$ of humerii had single nutrient foramen. Among them, 96\% were located on the middle 1/3 of anteromedial surface. Roul and Goyal $(2015)^{11}$ in their study observed that $94.6 \%$ of humerii had single nutrient foramen. In contrast, a study by Mysorekar $(1967)^{12}$ observed only $50 \%$ of humerii with single foramen. None of the humerii in our study had more than one foramen.

In the present study, foraminal index for right side was 56.31 and for left side was 56.88. Our findings are very much similar with that of Patel and Vora (2015). ${ }^{13}$ They reported foraminal index for right side was $\mathbf{5 6 . 7 2}$ and for left side was 57.27. We found there were no significant differences between right and left side for total length and for foraminal index. The findings of our study is very close with that of Xue et al. (2016), ${ }^{14}$ as there were no differences between sides in terms of length or nutrient foraminal index.

\section{Conclusion}

In the present study of dried humerii, we found that all the examined bones had single diaphyseal nutrient foramen. Majority of foramina $(81 \%)$ were present on middle $1 / 3$ of anteromedial surface of shaft of humerus. The direction of these foramina was similarly found in all bones i.e. towards the elbow joint. There were no significant differences between right and left side for total length and for foraminal index. The anatomical knowledge of nutrient foramina is important to orthopedic surgeons during surgical procedures on bones.

\section{References}

1. Malukar O, Joshi H. Diaphysial Nutrient Foramina in Long Bones and Miniature Long Bones. NJIRM. 2011;2(2):23-26.

2. Mysorekar VR, Nandedkar AN. Diaphysial nutrient foramina in human phalanges, J Anat. 1979;128(Pt2):315322.

3. Patake SM, Mysorekar VR. Diaphysial nutrient foramina in human metacarpals and metatarsals. J Anat. 1977;124(Pt 2):299-304.

4. Manjunath SH, Pramod R. A study of nutrient foramina in dry adult humerii of South Indian subjects. National Journal of Clinical Anatomy. 2012;1(2):76-80.

5. Datta AK. Essentials of Human Anatomy [Superior and Inferior Extremities]. 3rd ed. 60 Lenin Saranee, Kolkata: Current Books International; 2004 Nov.p.13.

6. Kulkarni GS, Limaye R. Nonunion of fractures of long bones. Textbook of Orthopedics and Trauma. 1st ed New Delhi. Jaypee Brothers medical publishers, 1999;2:1542-4. 
7. Hughes $\mathrm{H}$. The factors determining the direction of the canal for the nutrient artery in the long bones of mammals and birds. Acta Anat Basel 1952;15(3):261-280.

8. Laing PG. The arterial supply of adult humerus. The journal of Bone and Joint Surgery.1956;38A:1105-10.

9. Yaseen S, Nitya W, Ravinder M. Morphological and Topographical study of Nutrient foramina in adult humerii. International journal of innovative research and development. 2014;3(4):07-10.

10. Khan AS, Shah Z, Inayat Q. Anatomical variations in diaphyseal nutrient foramina of humerus in cadavers from Khyber Pakhtunkhwa, Pakistan. Khyber Medical University Journal. 2014;6(1):18-21.

11. Roul B, Goyal M. A Study of Nutrient Foramen in Long Bones of Superior Extremity in Human being. International Journal of Current Research in Life Sciences. 2015;4(4):198-200.
12. Mysorekar VR. Diaphysial nutrient foramina in human long bones. J Anat. 1967; 101(Pt4):813-22.

13. Patel SM, Vora RK. Anatomical study of nutrient foramina in long bones of human upper limbs. IAIM. 2015;2(8):9498.

14. Xue Z, Ding H, Hu C, Xu H, An Z. An anatomical study of the nutrient foramina of human humeral diaphysis. Med Sci Monit. 2016;22:1637-1645.

How to cite this article: Ghule SB, Vitore B, Mahajan AA. Anatomical study of nutrient foramina in humerus. Ind J Clin Anat Physiol. 2018;5(3):412-415. 